\title{
When $80 \%$ of Information is NOT in Big Data and Spread Sheets... You Need to Become a Leadership Anthropologist
}

\section{Dave Ulrich*}

Ross School of Business, University of Michigan, USA

Decades ago when I took my first "OB" course, I called my parents and told them I was shifting from studying law to studying "OB." They thought I would become a doctor (obstetrics). However, when I clarified that $\mathrm{OB}$ was an acronym for organizational behavior, they asked, "What is that?" While I could not fully explain to them what OB meant for a career, I was enraptured. I started to observe and analyze places I worked, restaurants where we ate, stores where we shopped, athletic teams I followed, church where I worshipped, and so forth. Because of my obsession with organizations, my psychologist wife told me I had a new disease, Organization Compulsive Disorder (OCD).

My passion for analyzing organizations led to a Ph.D. in numerical taxonomy (statistics) and dozens of major research projects where my colleagues and I theorized, collected data, analyzed results, and offered advice on organization practices.

However, in the process of studying organizations, I have realized that much of the organization phenomena I care about are not in spread sheets, big data, or open to traditional statistical analyses. Much of what I learn about organizations comes from careful observation. My experience is confirmed by Professor Wayne Brockbank, a thought leader in organization information, who has reported that 20 percent of information that can be analyzed about an organization is structured and embedded in traditional numbers, often susceptible to spread sheets and statistics. The advent of "big data" examines more carefully these data points to identify trends. Brockbank further claims though that the other 80 percent of information is unstructured and not easily quantifiable. This information comes from day-to-day living and is found in experience and observation.

Quantitative analysis (20\%)-that which works with existing data, identifies themes, and offers empirical insights-should be supplemented with qualitative data $(80 \%)$ - that which comes with observation, discerns discontinuities, and requires judgment.

Leaders and HR professionals, I counsel must recognize and use structured data; however, doing so is now often a table stake skill that many leaders should have already acquired. The most successful leaders and HR professionals go beyond the structured data and appreciate and rely even more on unstructured data. They look out the window at what is visible but not often seen. These leaders become organization anthropologists who seek ambiguity and are constantly exploring questions that are not yet or not easily answered. So, what do these leadership anthropologists do in studying the unstructured data that make them more effective?

\section{Listen for Things that Seem Counterintuitive}

I recently interviewed a new head of HR who came from outside the HR department. He discovered that his HR professionals were superb at managing talent: bringing good people into the organization and moving them through the organization. However, he said that the organization was facing major strategic changes: getting people was not the real problem. Finding the right people for the future and then creating a culture where they did their best was the bigger challenge facing his organization. After discussion, we found that his organization's "talent" practices were 70 to 80 percent up the "S-curve" of effectiveness, but the organization "culture" practices were 20 percent up the curve. Listening to his story taught me that he was a leadership anthropologist who recognizes the emerging culture demand and as I listened to him, I also was an anthropologist in recognizing the importance of organization culture more than talent.

Leaders sometimes hide behind titles, offices, and roles, like how the new HR head could have been content with his department succeeding at the traditional HR work. But anthropology leaders spend time outside their comfort zone. One leader went to the third shift to observe and "feel" employee morale. Another leader visited key customers who had left the business to learn why they left. Yet another leader used social media to have a world-wide town hall meeting to share her musings and seek input (often called a hackathon). An anthropologist leader might ask, "What do I observe or sense that does not readily fit into my existing ideology?"

\section{Surround Yourself with People Who See Things Differently}

Insecure leaders like to be respected and often surround themselves with people who think like they do or who may not be quite as good as they are. Effective anthropology leaders have both the self-confidence and curiosity to surround themselves with people who have new ideas and fresh insights. One of my favorite leadership coaching questions for leaders to ask others is, "What do you think?" This question encourages others to offer ideas on problems they may see and helps to build a creative environment.

\section{Experiment and be Willing to Fail and Learn}

I worked in a company where we developed this mantra: think big, test small, fail fast, learn always. This company was constantly innovating products, services, business models, and leadership actions. They found that they (and many other companies) were pretty good at thinking big and testing small. But they were not as good at failing fast and learning always. When failure was viewed as an opportunity, they began to increase innovation because people were not hiding from mistakes but sharing and learning from them.

As anthropologists, leaders are constantly observing what people do, then testing if these experiments are generalizable. Leader observers

*Corresponding author: Dave Ulrich, Professor, Ross School of Business, University of Michigan, USA, Tel: +1-801-653-9341; E-mail: dou@umich.edu

Received August 28, 2017; Accepted September 13, 2017; Published September 23, 2017

Citation: Ulrich D (2017) When $80 \%$ of Information is NOT in Big Data and Spread Sheets... You Need to Become a Leadership Anthropologist. J Bus Fin Aff 6: 287. doi: 10.4172/2167-0234.1000287

Copyright: (c) 2017 Ulrich D. This is an open-access article distributed under the terms of the Creative Commons Attribution License, which permits unrestricted use, distribution, and reproduction in any medium, provided the original author and source are credited. 
recognize that failure is a great opportunity to learn. These leaders celebrate the lessons of failure as much as the lessons of success. Another favorite leadership probe I encourage leaders to use is, "What did you learn from the last experience that you can adapt going forward?" This question encourages learning from more than dwelling on failure.

\section{Continually Navigate Paradox}

In our leadership studies, we find that people seek the holy grail of being an effective leader by attempting to find a single underlying factor that will ensure leadership effectiveness. In recent years, leaders were encouraged to have emotional intelligence, then it was learning agility (or grit, resilience, growth mindset, perseverance). In our research, navigating paradox has become the next wave in the evolution of leadership effectiveness.

Paradoxes exist when seemingly contradictory activities operate together. We experience paradoxes in daily life, as captured by these popular phrases: tough love, do more with less, oil and vinegar, sweet and sour, work/life balance, catch 22, go slow to go fast, good and evil, and so forth. When these seemingly inherent contradictions work together, success follows. Instead of focusing on "either/or," paradoxes emphasize "and/also" thinking.

Paradox navigation requires asking questions more than giving answers, not judging on a single dimension, and seeing the combination of ideas instead of a single idea. A leader might encourage paradox navigation by asking, "What are other options?" or "How else might we approach this problem?"

\section{Conclusion}

Being a leadership anthropologist requires a commitment to learning and letting go. Learn when relationships and ideas aren't working and be willing to let them go. In my teaching work, I find I need to have 20 to 25 percent new material every two years. This sounds easy, but it is enormously demanding over the decades. This requires letting go of ideas I might like, then constantly acquiring new stories, creating new tools, and asking new questions. 